\title{
RC frame structure strengthening by reason of insufficient concrete strength
}

\author{
P. Stepanek, I. Lanikova \& P. Simunek \\ Brno University of Technology, Czech Republic
}

\begin{abstract}
During the reconstruction of a university in Olomouc (Czech Republic) it was discovered that the concrete used in one load-bearing structure was of insufficient strength. The university building complex was constructed in the years 1955-1960. It is built from a reinforced concrete skeleton. The four-storey building is founded on RC footings and continuous footing. A detailed structural investigation of the structure of the first floor determined that the strength of the used concrete varied, ranging from concrete class C3/3.5 to C12/15. The original designed concrete class was $\mathrm{C} 10 / 13.5$, while the plain reinforcement utilised according to the original design was steel with a design strength of $180 \mathrm{MPa}$. Three structural repair variants were designed based on construction surveys:

- steel bandages for the columns and girders, and strengthening/supporting of the girders via steel cross-beams fitted to the bandages;

- steel bandages for the columns and girders, and strengthening of the girders via prestressing tendons;

- additional non-prestressed reinforcement of the structure by covering it with sprayed concrete.

Based on the economic (cost), structural and technical aspects (minimising of additional load), the variant using bandages with additional external prestressing of the majority of the girders via tendons was preferred.
\end{abstract}

Keywords: concrete, prestressing, bandage, frame, strengthening.

\section{Introduction}

The architectural design of the university building was created at Jiří Kroha's studio from 1950-1952, and construction took place in the years 1955-1960. The 
discussed structure is one part of a larger complex (in which individual buildings are separated by dilatation joints).

The structure is fabricated from a reinforced concrete skeleton and is founded on RC footings and continuous footing at different height levels.

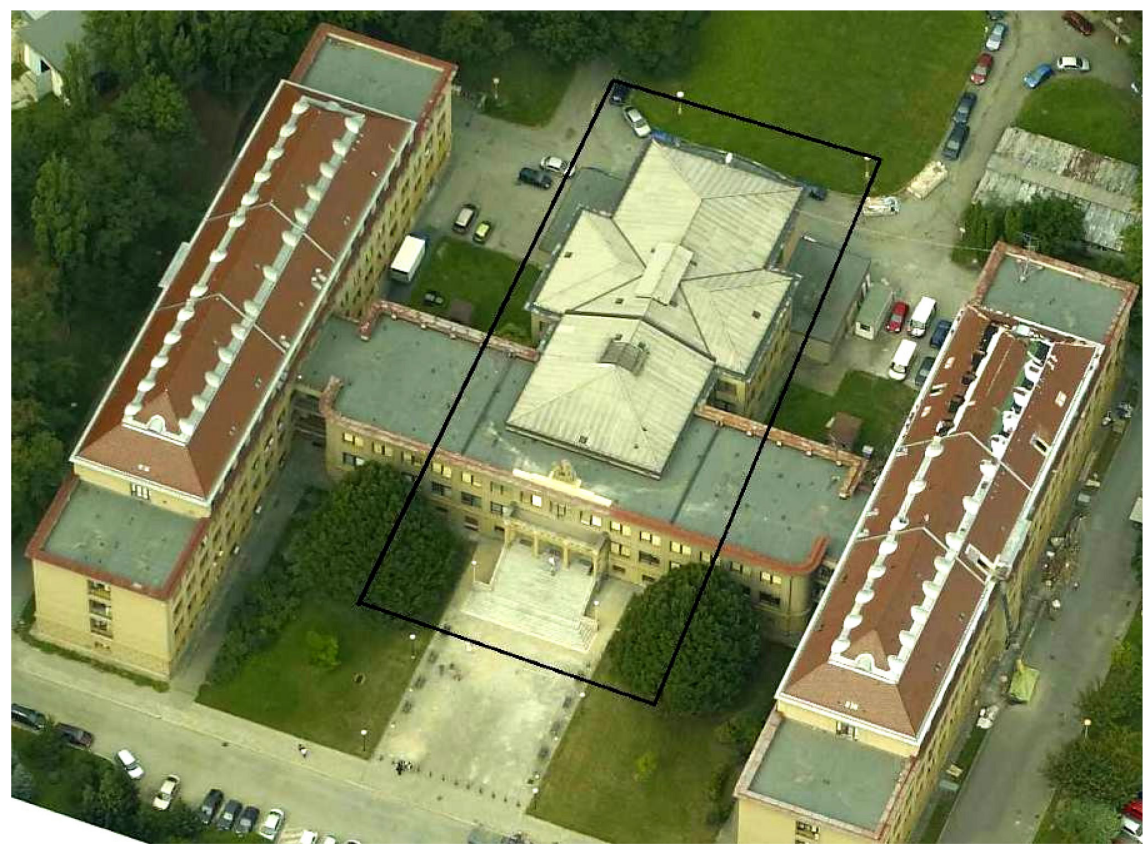

Figure 1: General view of the university complex.
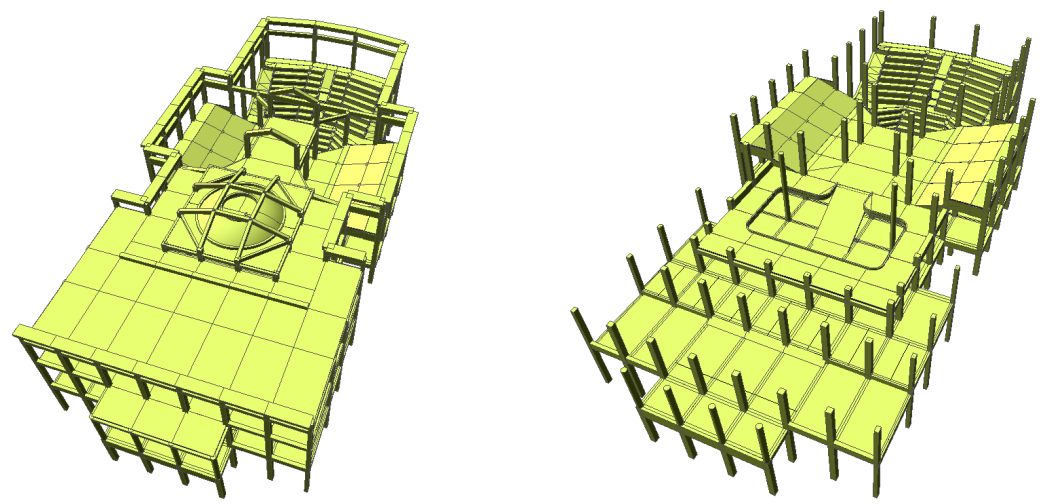

Figure 2: $\quad$ FEM computing model.

The first floor contains technical support facilities, workshops, storerooms, etc., while the second floor, which is on the level of the main entrance to the building, features a foyer and a large stepped lecture hall of two storeys in 
height. On the third floor there is a gallery overlooking the foyer, and two small sloped auditoriums and offices. The fourth floor houses the attic and elevator machine room. The roof structure above the foyer is formed from a wooden frame; above the lecture hall and small auditoriums it consists of rafters with steel roof truss girders. The bottom chords of these girders simultaneously support a ceramic hollow plate ceiling. A dome with a skylight arches across the area above the open foyer.

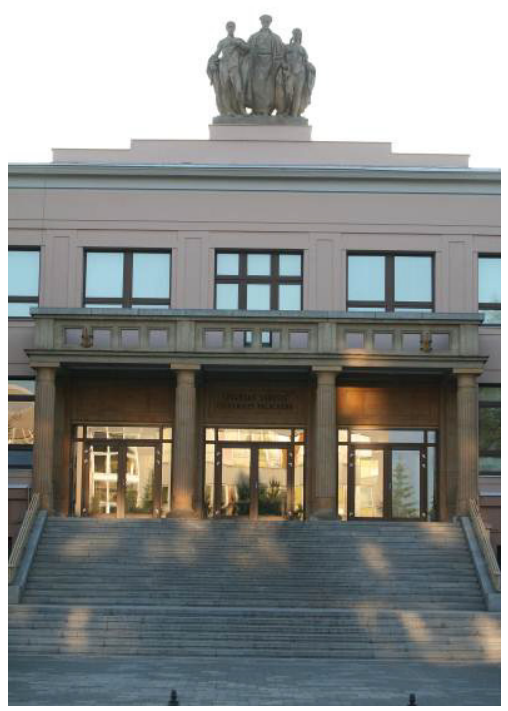

Figure 3: $\quad$ Front view.

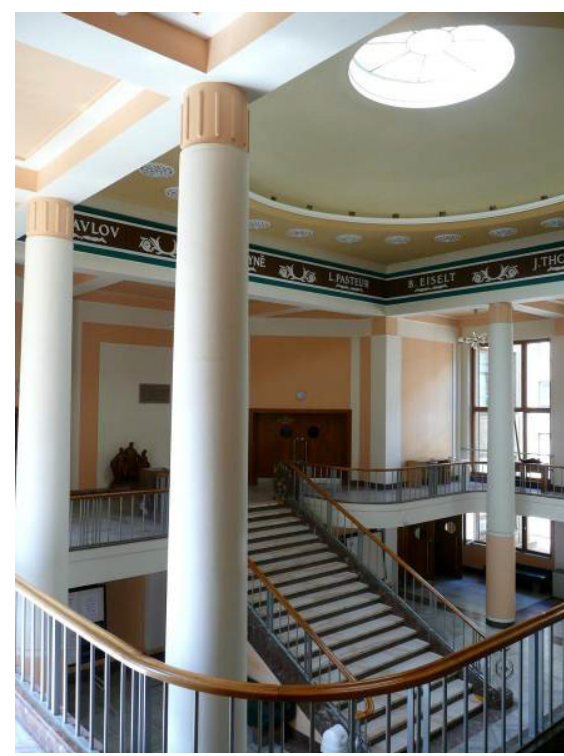

Figure 4: $\quad$ Foyer.

\section{Structural survey}

During the years 1996-2011 it was discovered that the concrete used in the loadbearing structures was of low (insufficient) strength (concrete class C4/5, C8/10, etc.).

In 2011 a detailed structural investigation was carried out in connection with the planned reconstruction of the building. This involved the inspection of the load-bearing RC structure of the columns on the first floor and the ceiling structure above the first floor, and was followed by a study of some of the columns on the second, third and fourth floor.

The strength of the concrete was assessed from cylinder drill cores. The concrete class used in the columns varied ranging from C3/3.5 to C9/12.5; in the case of the girders the concrete class ranged from C6/7.5 to $\mathrm{C} 9 / 12.5$ and the concrete strength of the ceiling structure was classified as class $\mathrm{C} 12 / 15$. The designed concrete class was B170 (C10/13.5). 
138 Structural Studies, Repairs and Maintenance of Heritage Architecture XIII
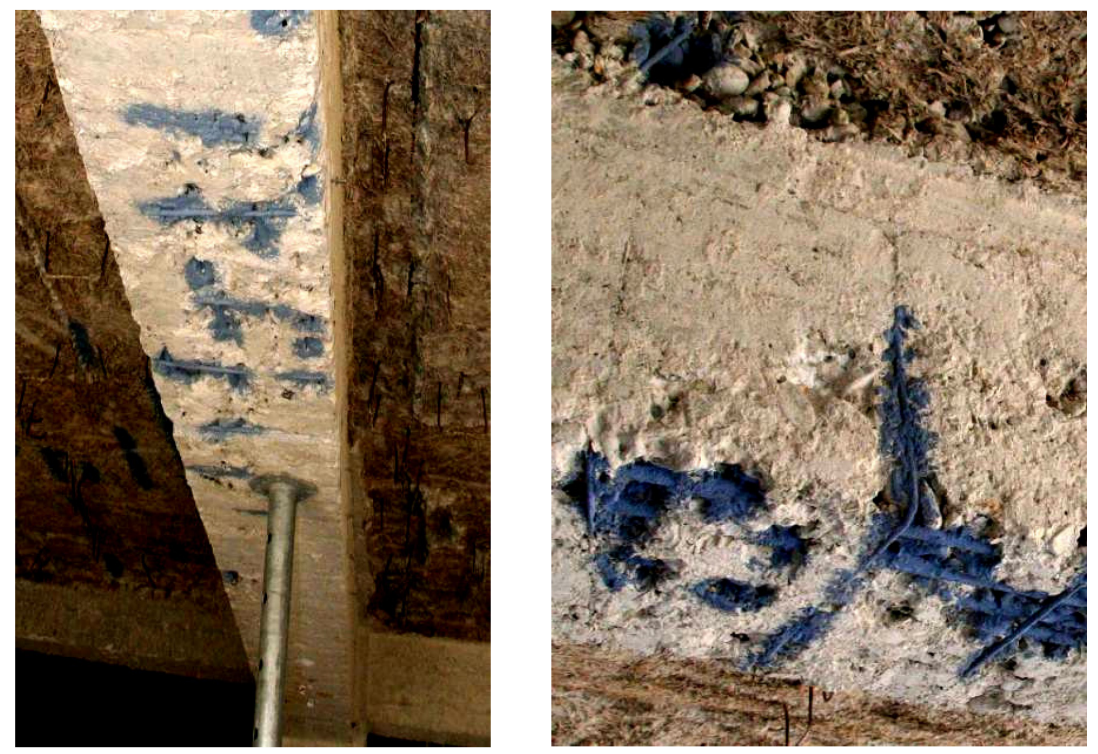

Figure 5: $\quad$ Local failures of a girder after plaster removal.
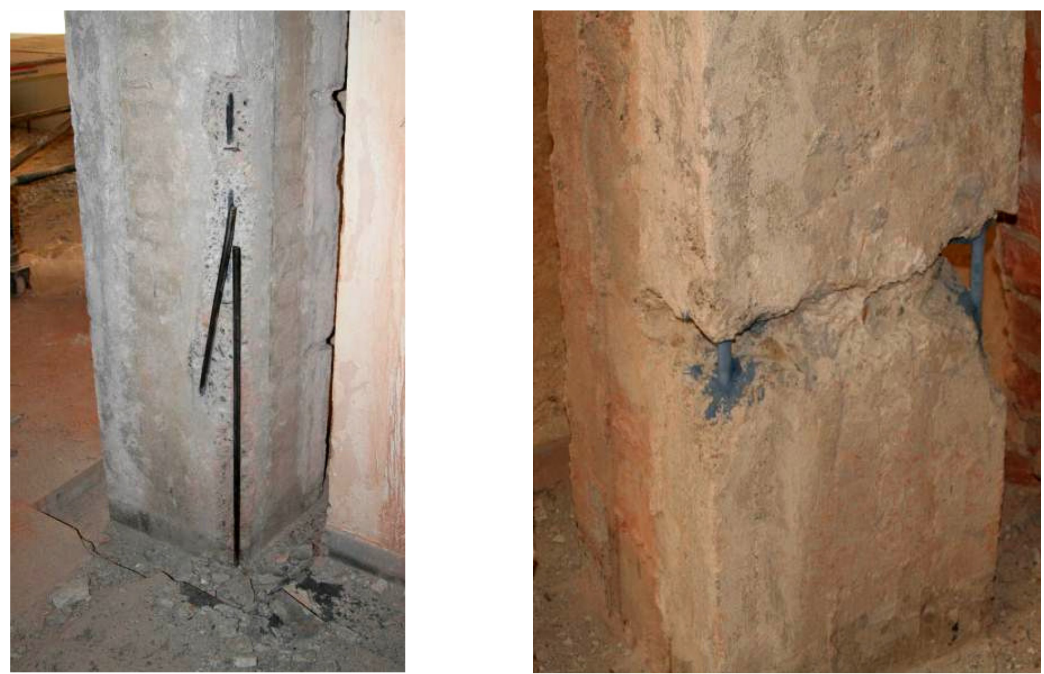

Figure 6: Local failures of a column after plaster removal. 


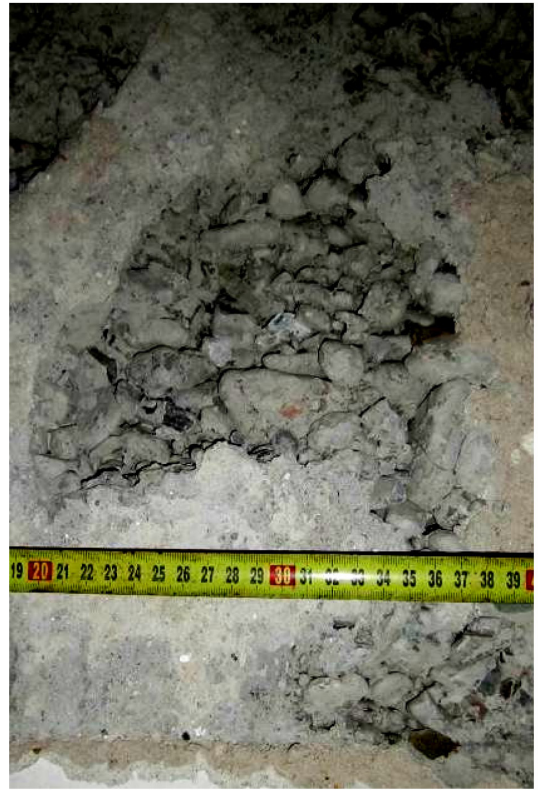

$\begin{array}{ll}\text { Figure 7: } & \begin{array}{l}\text { Faces of some } \\ \text { columns after plaster }\end{array}\end{array}$ removal.

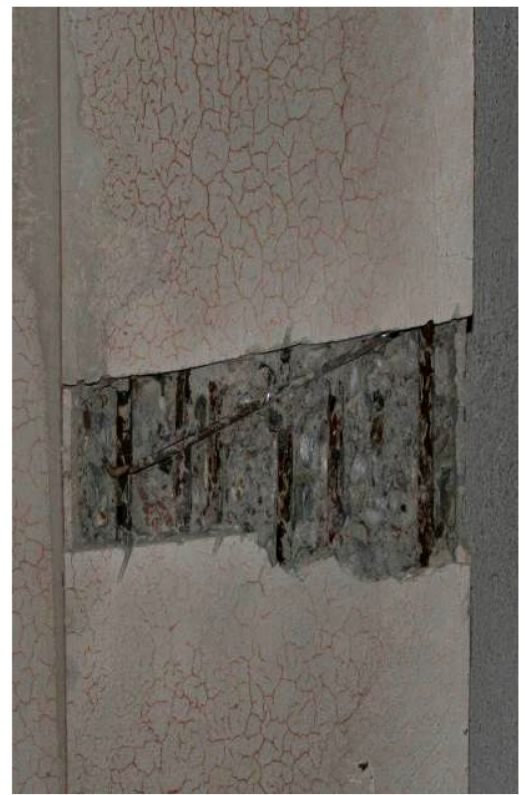

Figure 8: Checking the amount of reinforcement.

Plain steel bars were used as reinforcement, these being 10370 steel according to the original design with a design strength of $180 \mathrm{MPa}$, see standard [1]. The drawing documentation concerned with statics is incomplete. The amount and positioning of the reinforcement was verified for selected columns and girders and it more or less corresponded to the drawings (the difference was about 20\%).

The load-bearing structure did not demonstrate any serious static faults (deformations, cracks) when checked visually before the removal of plaster. After the plaster was gradually removed, local failures, insufficiencies in the quality of the concrete and inexact positioning of the reinforcement were detected (Figs. 5-8).

\section{Proposed repair plan}

The concrete used in the girders and columns on the first floor (and some on the second floor) was of lower strength (concrete class C3/3.5 to C9/12.5) than the values given by the EN 1992-1-1 code [3] (the lowest allowed class is C12/15). As a result, many columns do not meet ultimate limit state requirements. For this reason it was proposed that all the columns and girders situated within the first floor be bandaged.

In the investigated part of the building there is an inadequate amount of reinforcement in the areas of negative moments in the girder supports. The reinforcement in the middle of spans is not able to take the magnified forces 
from moments after the redistribution of internal forces (even if the proposed reduction of moments to column faces is performed). This is why it was also necessary to strengthen the horizontal girders.

Three rehabilitation variants were proposed:

- variant a): steel bandages for the columns, steel bandages for the girders and strengthening of the girders via steel cross-beams fitted to the bandages;

- variant b): steel bandages for the columns, steel bandages for the girders and strengthening of the girders via external prestressing tendons;

- variant c): additional reinforcement of the structure using sprayed concrete;

- variant d): the employment of bandages and reinforcement using FRP materials was also assessed (as a part of a studied alternative) but it was not considered for realisation.

Based on the economic, structural and technical aspects (minimising of additional load) of the proposed solutions, the variant using bandages and involving additional external prestressing of the majority of the girders was preferred. Some girders will be provided with steel supports; massive and lowloaded girders are considered to require bandages only. A three-dimensional model of the structure was set up to enable a detailed static assessment; it was analysed via FEM (Fig. 2).

\subsection{Column repair measure - bandage application}

The steel load-bearing profiles of the bandages were designed with regard to the actual state of deformation during bandage application; the state of stress in the bandage was determined on the basis of the deformation reserve of the existing reinforced concrete columns.

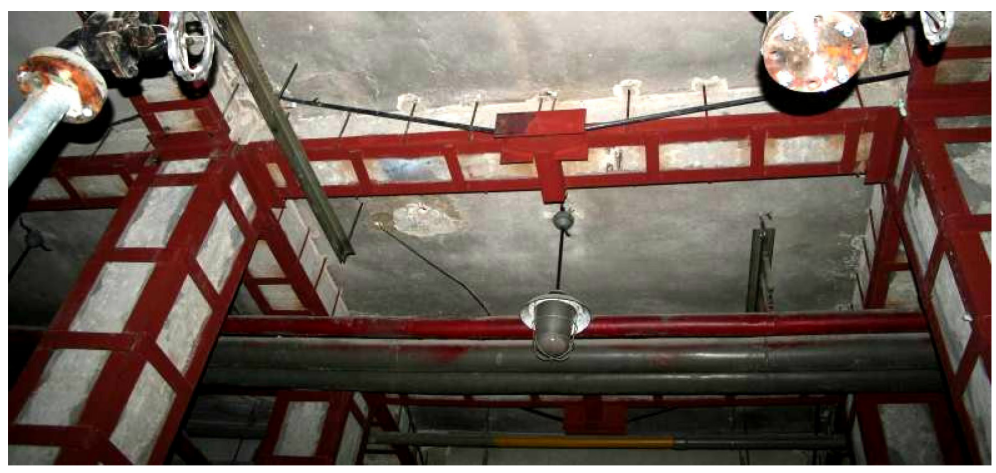

Figure 9: $\quad$ Column and beam bandage.

Transverse stress was applied to the columns via the incremental heating of the bandage strips by around $100^{\circ} \mathrm{C}$ and their welding to the corner angle sections. 
After the columns had been bandaged, it was also necessary to bandage most of the girders due to the low strength of the concrete from which they are constructed. The girders' bandages were fixed to the columns' bandages.

Assessment of the carrying capacity of bandaged columns was based on the stress state of each column, which corresponds to the load measured when fitting the bandage.

Only those steel angles that are located in the compression zone of the column were taken into account when evaluating the resistance of the column. Load capacity was calculated for the load eccentricity in the case of maximum normal force (and / or maximum moments in either direction) and also for the normal force of the combination which caused the greatest interaction between moments in mutually orthogonal directions (Fig. 10).

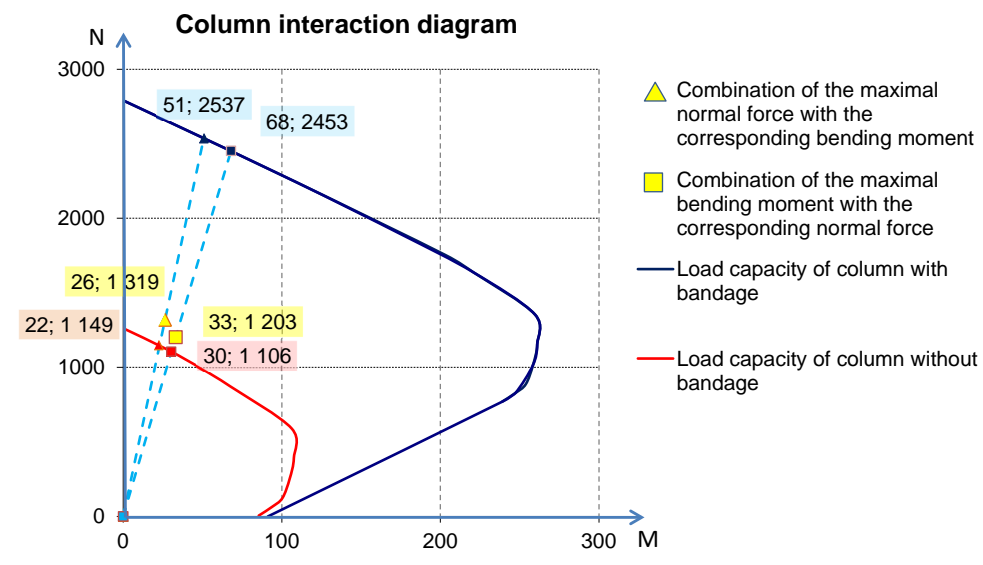

Figure 10: Column interaction diagram with and without consideration of bandage application.

\subsection{Strengthening of horizontal members via external prestressing tendons}

The magnitudes of the prestressing forces together with the geometry of the tendons' trajectories (the positions of deviators, anchors, etc.) were determined in such a way that the bending moments and shearing forces in the girders were partially balanced. Monostrands (HDPE 1670/1860 ø $12.7 \mathrm{~mm}$ or ø $15.2 \mathrm{~mm}$ ) were used for the prestressing; see Figs 11-13.

The upper deviators are formed from cylindrical steel plates with a radius of $400 \mathrm{~mm}$, which are installed in a mortar bed. The deviators are located on the sides of the columns. Lower deviators are formed from weldments, which are fixed directly to the bandages. Two parallel deviators are located at the bottoms of girders with a larger span (about $6 \mathrm{~m}$ ), and in such cases tendons are required on both sides of the girders. However, for the shorter span girders (i.e. $3.6 \mathrm{~m}$ ) only one deviator has been fitted in the middle of the span, and only one side of the beam has been provided with a tendon. Because of torsional moment, additional stirrups have to be welded on the bandages near the deviators. 


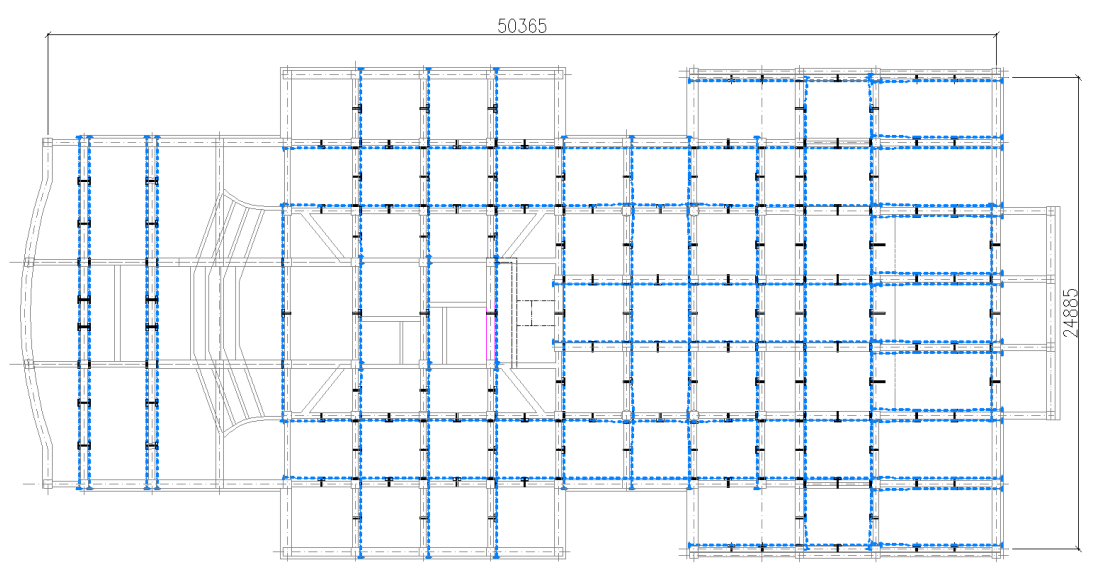

Figure 11: Ground plan of external prestressing.

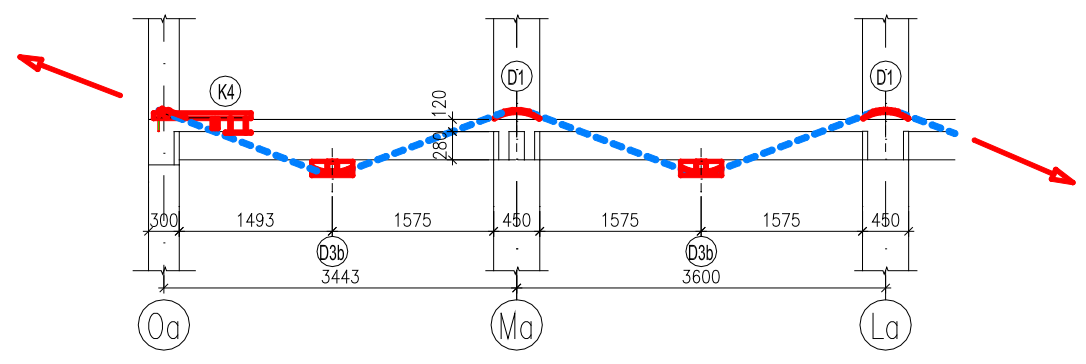

Figure 12: External tendon trajectories.
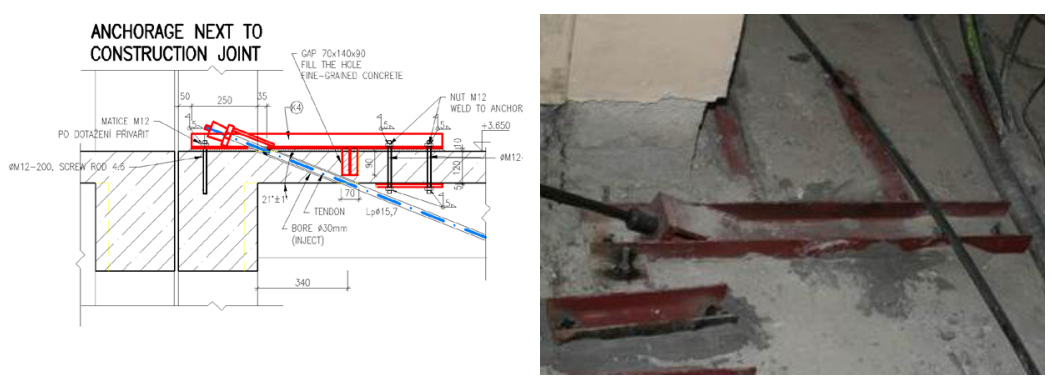

Figure 13: Detail of anchorage close to control gap.

The prestressing forces on one strand range from $70 \mathrm{kN}$ for the shorter span girders up to $125 \mathrm{kN}$ for the strands strengthening long span girders - these tendons were stressed in two phases. The second phase of stressing was carried out after new floors had been constructed. 


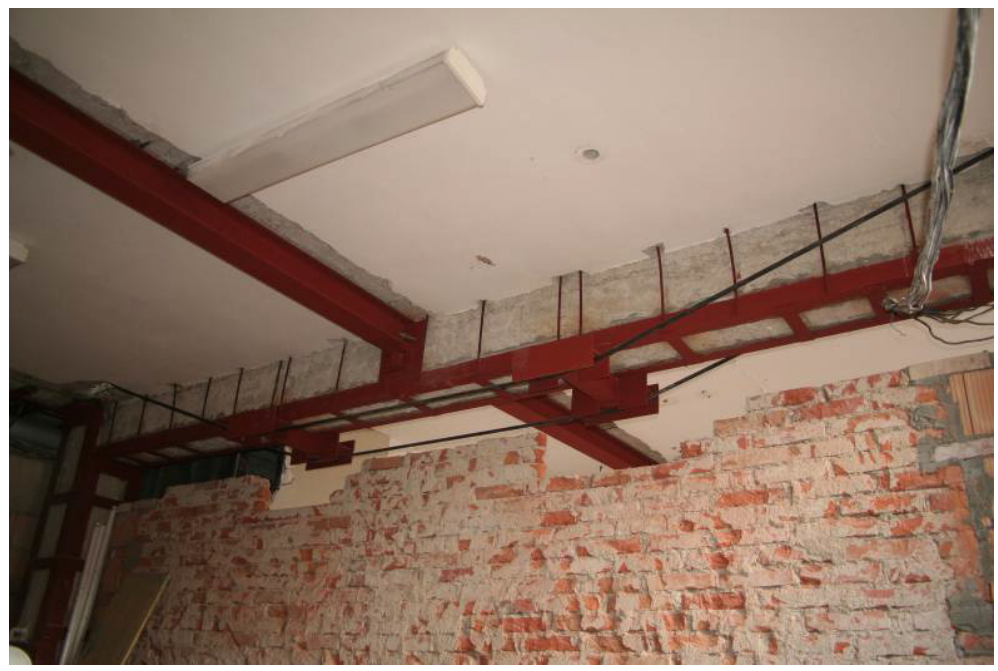

Figure 14: Beam bandage and external unbounded tendons.

\subsection{Original reinforcement method versus assumed structural behaviour}

As was mentioned above, there is an inadequate amount of reinforcement in the areas of negative moments in the girder supports. In addition, there are also structural areas with insufficient reinforcement within positive bending moment zones. Analysed structural behaviour and real current beam reinforcement has been compared (Figs 15 and 16).
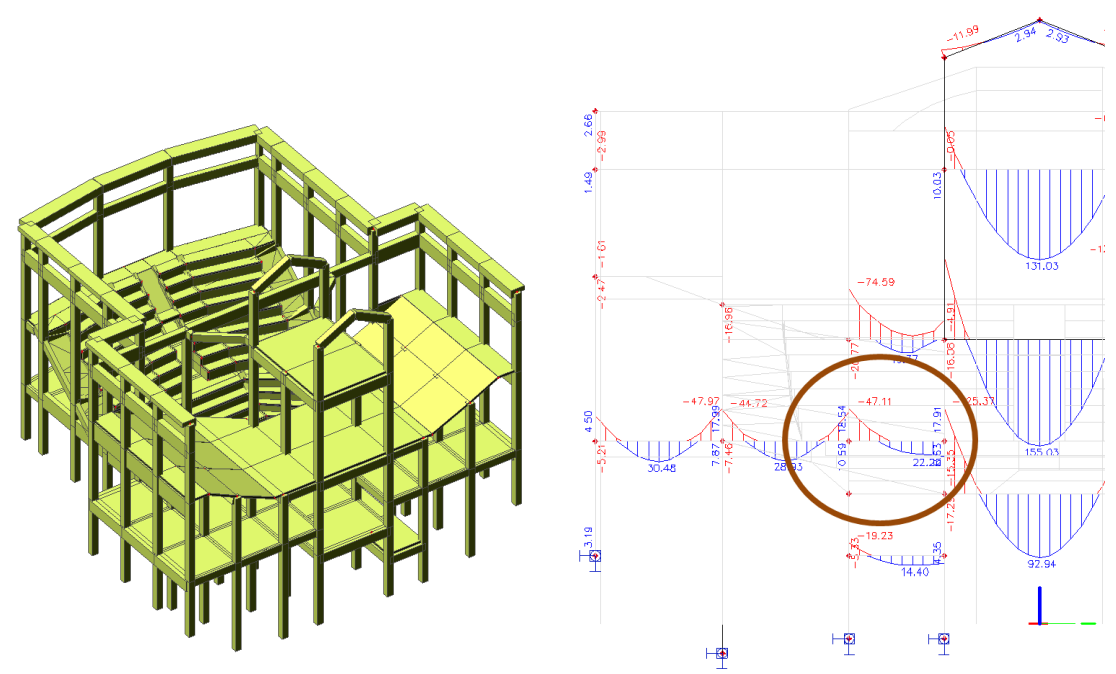

Figure 15: FEM model and calculated bending moments (before prestressing). 
The reinforcement in the bottom part of beam is inadequate. This was compensated for via the attachment of beam bandage to the column bandage, and prestressing (Fig. 17).

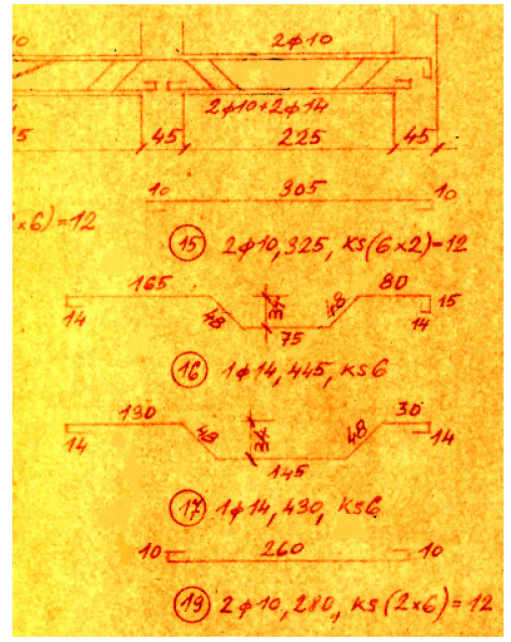

Figure 16: $\quad$ Original reinforce- Figure 17: ment drawing.

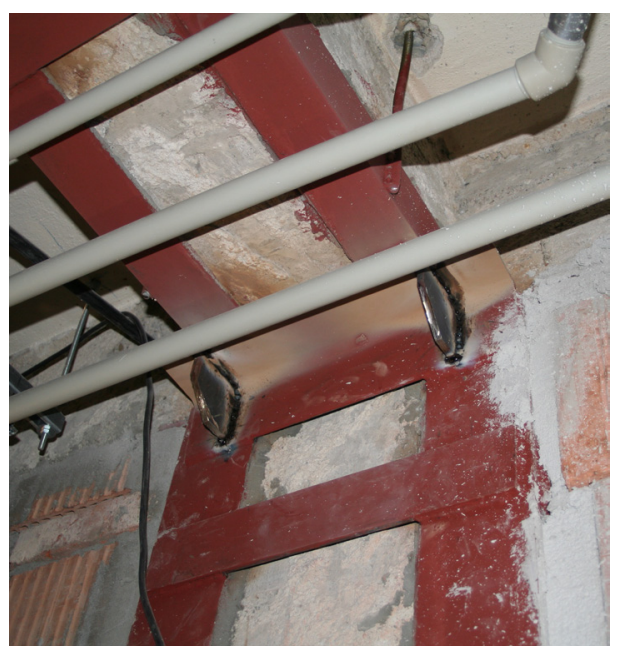

Beam zone with positive moment, strengthening.

\subsection{Strengthening of a brickwork wall with steel reinforcement}

The gable wall above the primary RC beam of foyer $m$ was cracked. The damage was caused by beam deflection (elastic, shrinkage and creep, etc.).
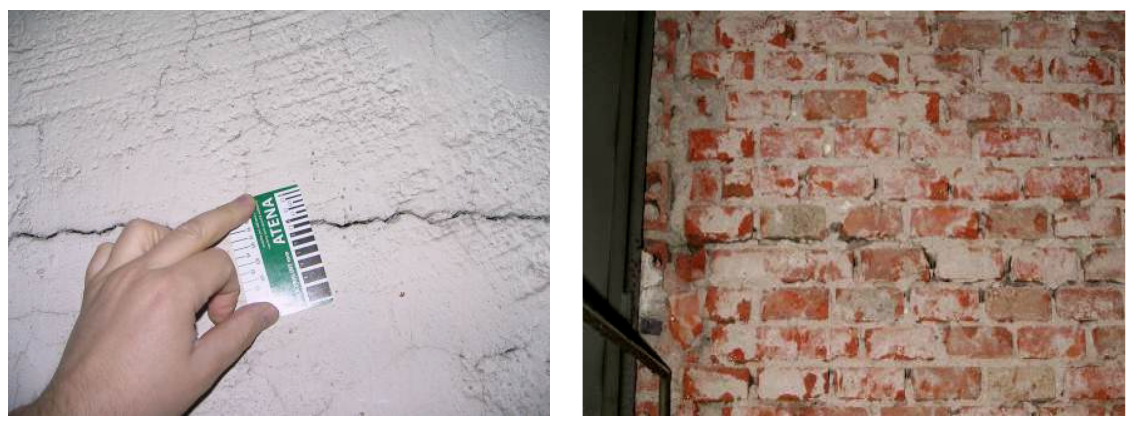

Figure 18: Gable wall crack.

The crack was stabilized; grouting and reinforcement stitching was an adequate solution (Figs 21 and 22). 


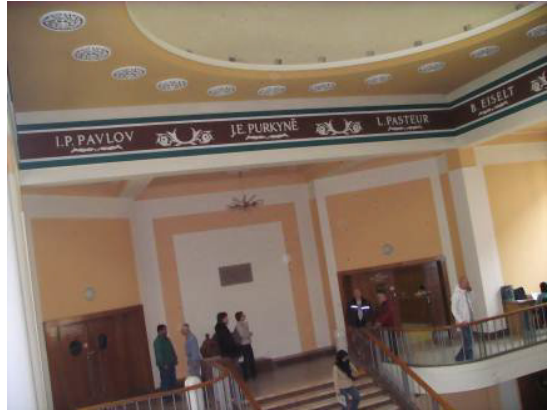

Figure 19: Primary beam, foyer.

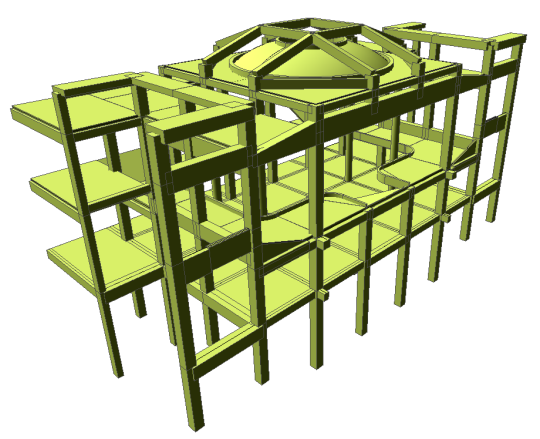

Figure 20: $\quad$ FEM model, foyer.

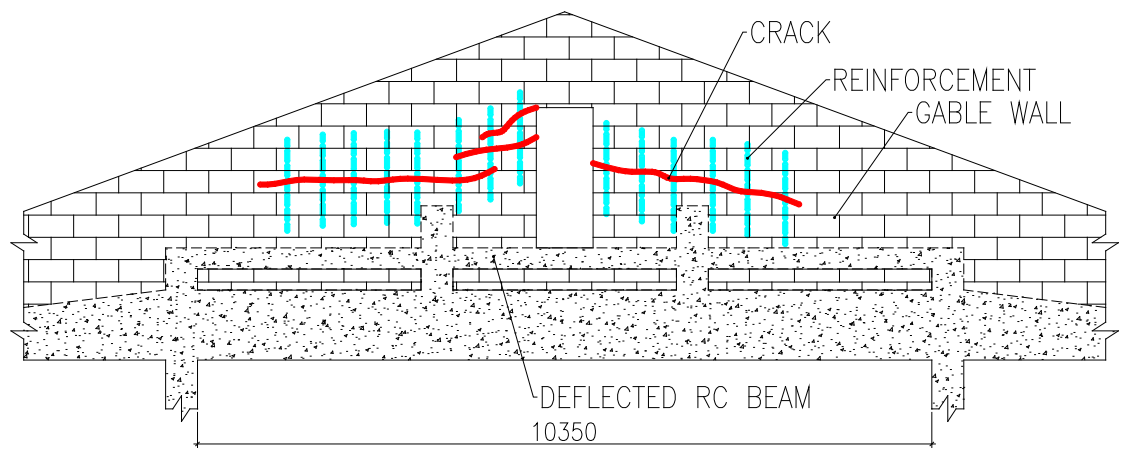

Figure 21: Gable wall, crack and repair with steel reinforcement.
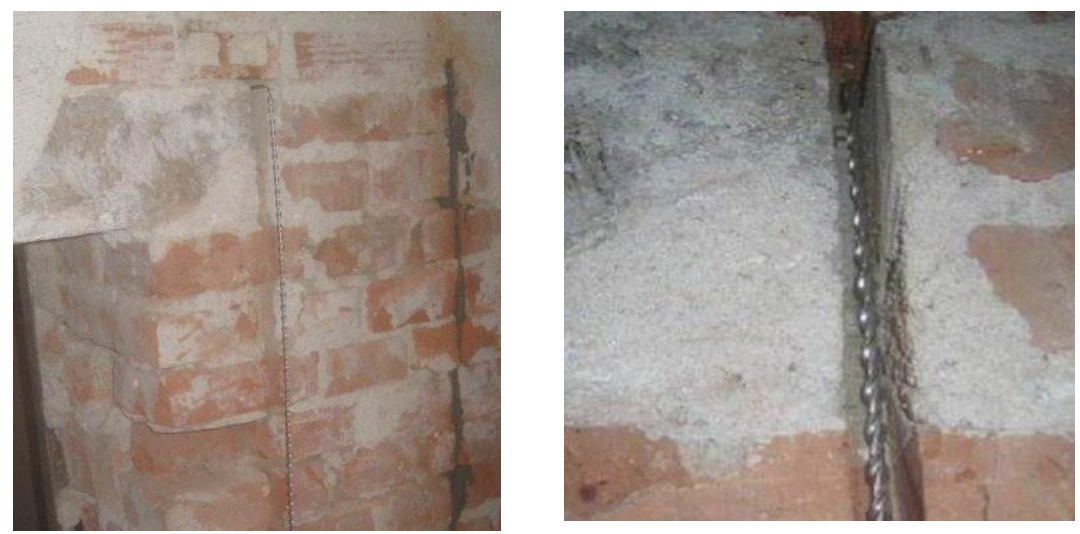

Figure 22: Gable wall, crack and repair with steel reinforcement. 


\section{Conclusion}

This otherwise well-kept and architecturally beautiful building has to undergo expensive repairs due to the poor quality and unsatisfactory strength of the concrete used to build it. Though the strength of the concrete used is very low, the building will not have to be demolished (as would occur if concrete containing aluminous cement had been used) and can be safely utilised for a long time after the completion of appropriate repairs. The comparison of different rehabilitation alternatives from the economic and technical perspective has allowed optimal solutions to be found that ensure the sufficient reliability and durability of the rehabilitated structure.

\section{Acknowledgements}

The presented results were obtained due to financial support provided by the Czech Science Foundation (GACR) within the research project GAP104/10/2153 "Composite structures based on high performance silicates and wood environment based optimisation and experimental verification" and financial support provided by the Ministry of Industry and Trade within the research project FR-TI4/159 "Light structures - progressive constructions from advanced composite materials”.

\section{References}

[1] ČSN ISO 13822: 2005 "Bases for design of structures - Assessment of existing structures", ČNI 2005

[2] ČSN EN 12504-1: 2009 "Testing concrete in structures - Part 1: Cored specimens - Taking, examining and testing in compression”, UNMZ 2009

[3] ČSN EN 1992-1-1 ed.2: 2011 Eurocode 2: "Design of concrete structures Part 1-1: General rules and rules for buildings”, UNMZ 2011

[4] http://www.vsl.net/Portals/0/vsl_lit/VSL_Construction_Systems_US.pdf, VSL construction systems 